\title{
Connoisseur Consumers, Dynamics Capabilities and Sustainability of Indonesian Single Origin Coffee Consumption
}

\author{
Mangku Purnomo ${ }^{1, *}$, Pardamean Daulai ${ }^{2}$, Medea Ramadhani Utomo ${ }^{1}$, Sugeng Riyanto ${ }^{1}$, Fenna \\ Otten $^{3}$, Heiko Faust ${ }^{3}$ \\ 1 Department of Socio-economics, Faculty of Agriculture, Brawijaya University, Jln. Veteran, Malang 65145, \\ Indonesia; mangku@ub.ac.id (M.P.); sugengriyanto@ub.ac.id (S.R.); medea@ub.ac.id (M.U.) \\ 2 Department of Sociology, Faculty of Law, Social Science and Politics, Open University, Indonesia; \\ pardameandaulay@ecampus.ut.ac.id (P.D.) \\ 3 Department of Human Geography, University of Göttingen, 37077 Göttingen, Germany; fenna.otten@geo- \\ uni-goettingen.de (F.O.); hfaust@gwdg.de (H.F.) \\ * Correspondence: mangku@ub.ac.id; Tel.: +62-0341-580054
}

\begin{abstract}
Sustainable consumption became the community's attention as the respond of worrying consumption growth direction that tends to excessively exploit nature without considering the continuity of the next generation. Take into account the growing coffee consumption in Indonesia, this article tries to prove whether the connoisseur consumers (CCs) are capable to mediate dynamics capabilities (DCs) of single origin coffee shops (SOCSs) and to encourage the consumption sustainability. In-depth interview to 30 SOCS managers, 60 baristas and 450 consumers, it is found that CCs are capable of supporting the business continuity of SOCSs because they are loyal consumers with the contribution of more than $20 \%$ from the total consumers. Correlation testing between connoisseurs' attributes and the number of visits also shows positive value. It means there is a significant relationship. In addition, related to the sustainability attribute, the existence of CCs has encouraged the practice of consumption sustainability. At the same time, CCs are capable to moderate SOCSs to improve sensing, seizing, and transforming shop management to put up with the competition. Based on the above findings, CCs are moderating SOCSs in improving their DCs to be more potential in improving the sustainable consumption of coffee commodity in the future.
\end{abstract}

Keywords: coffee shop, single origin, connoisseur consumers, sustainable consumption, dynamics capabilities

\section{Introduction}

Between agro-food products, coffee is the first commodity to quarrel in ethic attribute and sustainability such as fair trade, organics, premium price, as well as justified value chain issues ([1][3]. Several consumers' culture specialists mention that the phenomenon is part of "third wave coffee" where coffee is not only a commodity with strong cultural character but also a worldwide global business [4]-[7]. Now, the development of coffee consumption trend is fast and dynamic, even several consumers culture observers are building "fourth wave" theory where global coffee consumption will lead to coffee consumption model with the best quality becoming popular trend as well as extended business to build new supply chain that is different from current condition [8]. Coffee has shifted from business involving the control of traditional mean of production such as land, 
capital, and technology, to control over the means of symbolic production in extracting surplus value through global trade [4].

At the same time, the concern of parties on the unjustified distribution of coffee margin especially on the producer side namely the farmers have encouraged fair trade movement [9], [10]. Specialty coffee becomes one of the alternatives to liberate the producer from the unjustified coffee market structure [8], [11], [12]. Single origin coffee is the next more realistic strategy to give protection to the uniqueness of growing and developing origin coffee as well as its cultural characteristics [2], [13]. Geographical indication becomes one of the strategies not only to serve the origin tracked issue but also to protect the uniqueness of coffee and its culture [14], [15]. Despite small market share, since early 2000 until now, the existence of single origin coffee market has given the alternative and new perspective where coffee obtain premium price and slowly change the coffee consumption globally [13], [16], [17].

Many kinds of research on coffee mainly took the theme on lifestyle or social place of millennial [18], consumers loyalty and branding [19], culture and locality [20]-[22], and political movement [23]. Several kinds of research concerning coffee consumption are focusing too much on the ethics and sustainability issues [24], [25], while issues related to evolution side of the institutional coffee business at the local level do not get enough attention. In the economic aspect, there are so many information especially for supply theme and impact of the development of new coffee business networks with the farmers' welfare including the role of farmer group and cooperative [11], [24], [26], [27]. At the same time, many pieces of research on coffee focus too much on the personal preference related to taste [28] and other motives where institutional aspects of the economy, especially related to SOCSs business, are relatively rare to be discussed.

Observing the developing consumption growth throughout the year, coffee business is still considered as an interesting and profitable business because it is a most dynamic business in facing consumers culture development including technology [9], [29]. Consumption of coffee expected to increase 0.06 million bags from 3,09 million bags in 2016 to 3.15 million bags of green bean equivalent (GBE) in 2017 [30]. Additionally, retail coffee shops tend to focus on high quality specialty coffees due to increasing numbers of connoisseur's consumers [9]. At the same time production of Indonesia Arabica coffee is also seen rising slightly to 1.4 million bags from 1.2 million bags in 2017 according to the United State Department of Agriculture (USDA) [31]. Thus, this article focuses on the effort of acknowledging how connoisseur consumers moderate the shop managers to build their dynamics capabilities to draw clearer sustainability consumption on the coffee mechanism. This is in line with the wave direction of four coffees where single origin or country origin become an important issue along with the better coffee seed quality in the market [8], [9]. Locality as the culture setting also heavily affects the consumers behavior including coffee business [32] that is what this research is strategic enough because it raises the dynamic of coffee shop business in developing country that starts to build single origin coffee as a new commodity in the coffee market [14]. Thus, it is important to study the dynamic of this "coffee house" business at the local level especially its sustainability consumption, connoisseurs' role, and strategy of the managers in winning the competition. 


\section{Theoretical Frameworks}

Connoisseur consumers (CCs) are a consumers community that has more attention to the goods they buy [33] such as the origin of the goods, quality, friendliness on the environment, and other ethnic attributes. Theoretically, their consumer behavior is relatively sustainable because they have specific attention to the environmental issues as well as having the willingness to pay for environmentally friendly products better than general consumers [34]. They have the tendency to try understanding, evaluating, and appreciating consumption objects subjectively showing its preference toward certain coffee such as the origin of coffee, serving method, and others. Connoisseurs enjoy more of its behavior as the leisure activity as well as emphasizing the different self-identity with many of consumers group where one of its characteristics is empathy to the environment, does not have a problem with the price, subjectively care to the goods and service they consume [33]. Furthermore, CCs builds its own subculture that is different from most consumers. Thus, they are more close to the coffee experts than most consumers. Hence, it is very common for the SOCSs managers to respond to the existence of CCs by designing business familiar to their needs to obtain their loyalty.

They are not the only important one as visitors, CCs also has the ability to build community and generate new subculture and social capital that can support the existence of SOCSs. Even small existence of CCs has the potential to build specific consumers community, not only between their own but also consumers in general. Figure 1 shows that CCs can attract other consumers both regular or general visitors and outstanding professional to build social modal and new subculture [33], [35], [36]. Thus, the existence of CCs will be able to help single origin coffee shop to build a community of its consumers so that they will not only rely on the impulse consumers but also special consumers driven by CCs. Based on the above description, this article specifically analyzes whether the existence of connoisseur consumers between the consumers of single origin coffee shop will be able to improve dynamic dynamics capabilities of SOCSs and build sustainability consumption of single origin coffee.

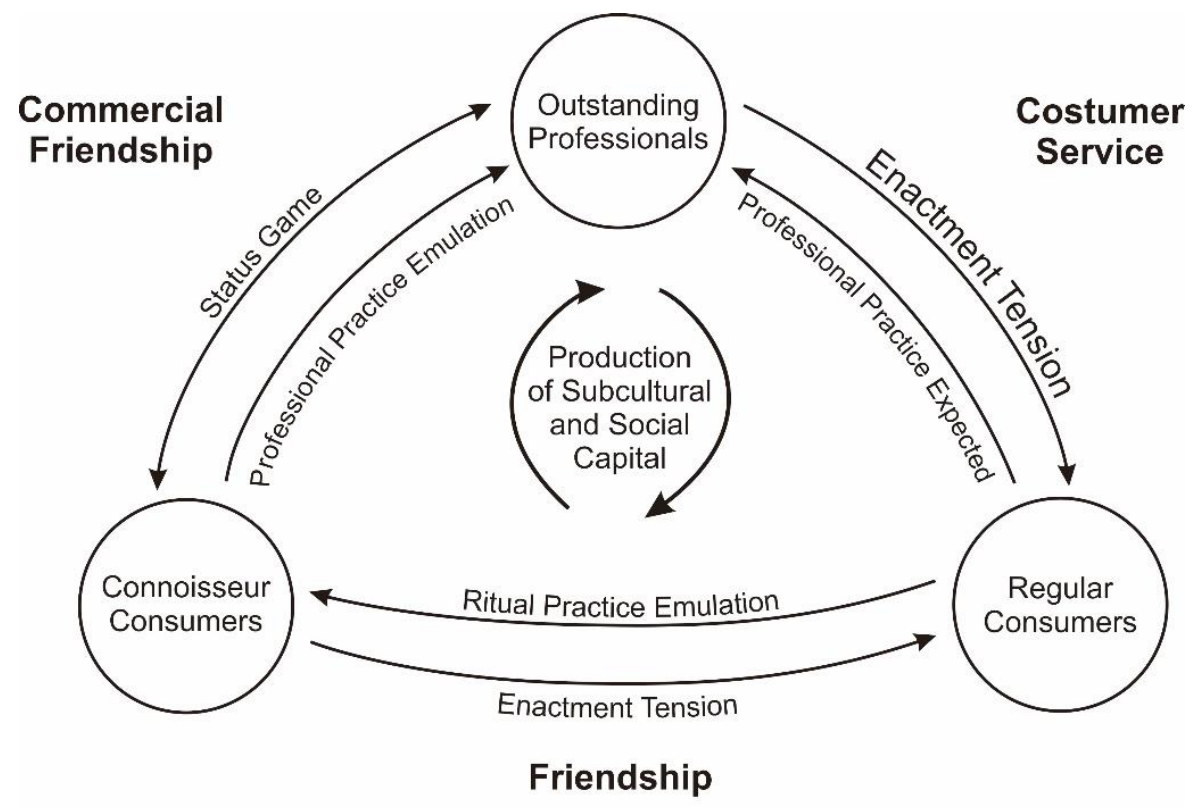

Pigure 1. Connoisseurship consumption community (adapted from Quintão et al., 2017b)

On the dynamic capabilities side, the existence of CCs as the market segment is relatively more loyal with clearer preference than most consumers, its potential facilitates the company in sensing, 
seizing, and transforming the company to be more directed relatively. For example, the huge existence of CCs in the consumers' structure in a company facilitates the managers in detecting what knowledge that will likely to be asked by them. The company can also anticipate it by giving enough education to its personnel who will communicate with CCs. So, the existence of CCs will facilitate the company to detect what are required needs to serve the typology of such consumers. Analysis ability on the external demand to skillfully change the organization to answer those challenges is one of the signs that a company has good DCs [37].

Dynamics capabilities (DCs) is a theory emerging to answer why many business institutions that have dominated the resources are useful in the production process, having strong HR, and solid system that will collapse in facing the competition, instead the institution has the ability to survive and even develop rapidly. According to the initiator, dynamics capabilities not only count the corporate mastery of assets and human resources, but also network, the ability of the institution itself to sense, seize, and actively transform the value and management of the organization to be responsive toward change and competition [38], [39]. DCs are an accumulative process of the company's social interaction. It is indigenous in nature and owned by a company so that it is impossible to be imitated by other companies because DCs involve "distinct skills, processes, procedures, organizational structures, decision rules, and disciplines." [37].

Moreover, it will be easier for the company to choose the most effective strategy to control its resources needed to serve the CCs better in keeping their loyalty. CCs have a relatively open characteristic with the barista as commonly seen in the coffee shop, it has helped the manager to quickly improve their business model. It will allow the company to quickly design and refined a business model that can truly fulfill the CCs demands especially the knowledge of sale and purchase products. A model business that is capable to utilize the mapped resources in accordance with the needs of consumers will have strong dynamic capabilities. This intellectual property will also be the character of the company with competitors so that the concepts or innovations characterizing the company are difficult to be replicated by other companies [37].

On the seizing side, management builds two strategies namely anticipating the competitor's reaction that can disturb the sustainability of the company and use the intellectual property to maintain dominance. This intellectual property is an asset from the company that is impossible to be imitated by other companies due to the rights claim attached to that company [37] so the company has the monopoly. In SSCS context, this intellectual property can be in the form of concept development of the shop, other than the difficulty to be imitated due to its originality, shame will be one of the barriers for imitating process. Meanwhile, in anticipating the reaction from the competitor, especially traditional coffee shop, the specific strategy can be used to anticipate the price and promotion or additional facilities provision can also be an option [9]. This strategy is one of the ways for the manager in designing and refining business model to be able to seize more effectively. 


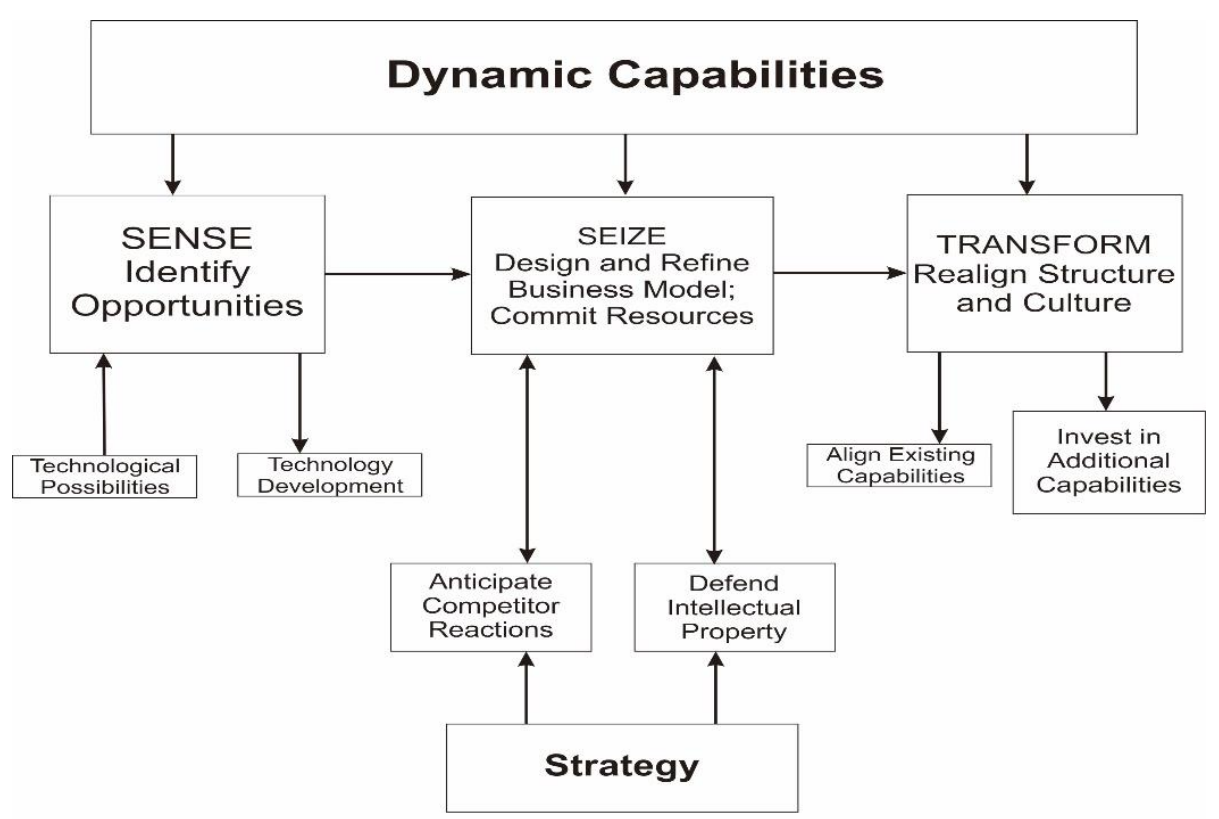

Pigure 2. Simplified schema of dynamics capabilities, business model, and strategy

Meanwhile, in transforming the company periodically so that the structure and its culture will be more responsive to changes, the manager should do alliance process and investment to improve the company's capability. The ability to always build flexible value and move all parties is very important for the company in order to adjust with practical community needs. Partnership with "sharing" principle between Uber and personal car owners means sharing risk and resources so that the company becomes more competitive. At the same time, the company will be able to invest more carefully and it will have a big impact on improving their dynamics capabilities [37]. It means that they will be able to integrate goods, service and knowledge components into unique combinations that solve strategically important customer specific problems", the specific problem in this research is the existence of CCs [40].

What is the relationship between sustainability and dynamics capabilities? Referring to several views, sustainability is a measure to analyze whether an economic, ecological and social aspect is able to grow and develop jointly without being defeated by one and another. There is a balance between socio-economic and environmental sustainability for sustainability, not only for human existence but also the existence of civilization and environment. On the economic aspect, based on the definition by [41] who stated that "sustainable consumption behavior as individual acts of satisfying needs in different areas of life by acquiring, using and disposing goods and services that do not compromise the ecological and socio-economic conditions of all people (currently living or in the future) to satisfy their own needs". It contains a meaning that consumption on the service and goods will not only compromise with ecological and socio-economic conditions for the sustainability of the next generation [41].

Furthermore, [41] centralized the ways to analyze sustainable consumption by involving three main dimensions namely the dimensions of sustainability, consumption phase, and consumption area and one specific indicator, namely the impact as a result of consumption. Sustainability dimension includes ecological and social-economic sustainability, while consumption phase involves the acquisition, usage, and disposal, and consumption area involves food, housing, mobility, clothing, and others. Meanwhile, the impact indicator as the follower from consumption activity is 
seen from both the good and bad sides by a certain degree. Furthermore, sustainability can also be seen in two sides namely SOCSs as a business institution and CCs as active consumers.

On the institutional business, sustainability can be verified from the efforts by the company starting from the effort in transferring knowledge to the customers [42], efficient energy consumption [43], [44], transparent business process [45], and reduce production waste [46]. Those four contributions can be seen from three main activities from coffee business namely production and consumption process [47], as well as marketing [48] where the existence of CCs "force" the shop to do activities in encouraging coffee business process to be more sustainable. How much the CCs contribution in encouraging the company to transform into more sustainable, and how is the consumers' behavior itself in keeping the sustainable values will be able to be analyzed.

\section{Materials and Methods}

The research was conducted in Malang, the second biggest city in East Java Province with a population of more than 600 thousand people, with significant development of coffee shops in the last ten years. Not less than 250 coffee shops with more than 100 SOCSs will keep growing over time. We have conducted an in-depth interview to 30 SOCSs owners as the key informants for two months to construct what strategies they have carried out in facing tighter competition with usual coffee shops. At the same times, we also conducted observation and discussion with SOCSs customers to get an in-depth impression regarding the atmosphere, their preference and respond to their favorite SOCSs. Meanwhile, sampling respondents with convenience sampling as many as 450 consumers were conducted so that the researchers can obtain respondents who have a deep understanding of single origin coffee to facilitate the data extraction process and respondents who have consumed single origin coffee. Figure 3 stratified random sampling in determining the number of respondents and informants.

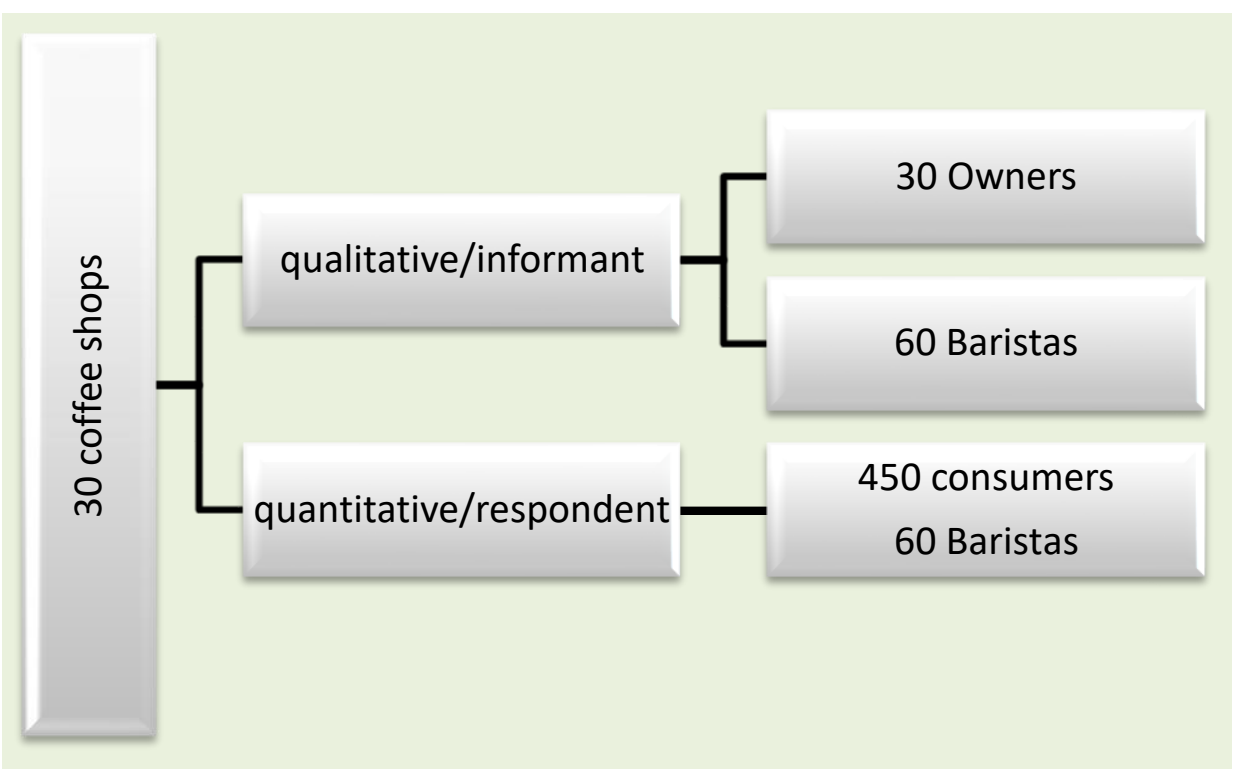

Figure 3. Respondents and Informants Sampling Technique

Furthermore, we asked 60 baristas to record the behavior of 450 consumers in two weeks, do they directly order the single origin coffee type, ask barista's help, or order coffee other than the single origin. The method of ordering is an indication of the costumers' intensity on the coffee they drink as potential connoisseurs or connoisseur candidate. Thus, this research simultaneously uses 
quantitative and qualitative approaches to explain the existence of CCs, their role in driving sustainable consumption as well as improving Dynamics capabilities of SOCSs.

The quantitative approach aims to calculate the potential existence of CCs and measure the relationship between CCs attributes, namely the level of manager's knowledge of coffee, coffee shop image, a variety of coffee, barista's communication skills, and the quality of coffee serving techniques with the number of visitors. Simple descriptive statistical analysis is used because this research focuses more on explaining social processes. Thus, the results of statistical calculations can be used to strengthen the qualitative findings. This explanatory analysis is used to examine causality or causal relationships between variables or to prove whether there is a relationship between purchasing decisions and various attributes of connoisseurs.

Meanwhile, qualitative analysis is used to capture what strategies are built by managers of SOCs to improve DCs in the middle of the competition. How they do sensing, seizing, and transforming will be described qualitatively because it involves a social process that is relatively difficult to explain with a quantitative approach. Therefore, the qualitative content analysis approach [49], especially the strategies developed by managers of good SOCSs, starts from the sensing, seizing, and transforming processes. Simultaneously, theme analysis [50] was also used to map whether various sustainability attributes exist in the response of SOCSs in their efforts to provide services from the existence of CCs.

\section{Results}

\subsection{Connoisseurs Community of SOCSs}

It is quite difficult to find the existence of connoisseurs among visitors because they usually get along with other visitors. Thus, special methods are needed to detect them. One of the ways is to check the existence of connoisseur consumers among shop visitors by surveying the way they order the coffee menu. If the customer chooses his own coffee, both the type and method of serving, then they are certain to have special attention to the goods they buy as a characteristic of connoisseur consumers. Independently choosing the type of coffee, the way to present it, the high intensity of the visit each month are indications of the connoisseur consumers. Interview with baristas has confirmed that the coffee lovers often started a conversation with baristas about the information of coffee origin, serving techniques, as well as the character of the taste and aroma. In detail, the census of all sample shop visitors between March and April 2018 is presented in table 1.

Table 1. Percentage of connoisseurs in KKSO

\begin{tabular}{llrrr}
\hline Indicator of connoisseur & $\begin{array}{l}\text { Arrival } \\
\text { intensity } \\
\text { (month) }\end{array}$ & $\begin{array}{l}\text { Number } \\
\text { respondents }\end{array}$ & $\begin{array}{l}\text { Percentage } \\
\text { (\%) }\end{array}$ \\
\hline Individually choosing the type of coffee and the & $\begin{array}{l}1-5 \text { times } \\
\text { serving technique }\end{array}$ & $\begin{array}{r}\text { 6-10 times } \\
\text { Ask for barista's advice for coffee type and }\end{array}$ & 30 & 8.89 \\
serving technique & $11-15$ times & 25 & 5.56 \\
& 6-10 times & 50 & 11.11 \\
Giving the option to the barista in selecting the & $11-15$ times & 56 & 12.44 \\
coffee and serving technique & $1-5$ times & 55 & 12.22 \\
& $6-10$ times & 80 & 17.78 \\
\hline
\end{tabular}


Total

450

100.00

Source: primary data processed $2018(\mathrm{~N}=450)$

Furthermore, to ensure the existence of connoisseur costumers, we then examine whether the connoisseur attributes such as the depth of barista knowledge of coffee, barista skills, shop image, coffee variation, barista communication skills, and serving technique have a relationship with an increase in the number of consumers. If the three components all show a positive correlation with the number of customers, it can be determined that connoisseur customers do grow and develop among customers and are able to build communities. So, if the percentage of connoisseur potential in table 1 and the correlation test between the connoisseurs attributes and the number of visitors is in line, then the existence of connoisseurs as the support of SOCSs has been verified.

Table 2. Correlation between indicator connoisseurs with Number of Customers

\begin{tabular}{lcc}
\hline CCs Attributes & $\begin{array}{c}\text { Correlation } \\
\text { coefficient }\end{array}$ & Sig (2-tailed) \\
\hline $\begin{array}{l}\text { The level of manager's knowledge } \\
\text { about coffee }\end{array}$ & 0.634 & 0.004 \\
$\begin{array}{l}\text { Image of the Shop (café or coffee } \\
\text { shop) }\end{array}$ & 0.493 & 0.032 \\
Variation of coffee & 0.644 & 0.003 \\
Barista Communication Skills & 0.621 & 0.003 \\
Coffee serving technique & 0.453 & 0.031 \\
\hline
\end{tabular}

Source: Primary Data Processed (2018) (N=450)

Spearman rank correlation analysis in table 2 shows a significant value between the depth of knowledge and the number of customers' variables below 0.05 equal to 0.004 , it means there is a correlation or relationship. Meanwhile, the value of the correlation coefficient of 0.634 shows a strong relationship between the depth of knowledge and the number of customers, it can be said that the deeper the barista's knowledge about single origin coffee the bigger the potential to increase the number of SOCSs customers. This is supported by the opinion of the managers of SOCS that barista's knowledge is an important factor in their recruitment other than friendliness and work discipline. According to the shop managers, CCs not only asked the origin and quality of the coffee they ordered but also the serving techniques and characters of various types of coffee. Managers or baristas are required to have sufficient knowledge about single origin coffee. Even some managers say that CCs are very easy to move to another shop if they feel there is a peculiarity of the coffee they drink, especially the consistency of flavor from day to day.

In addition to the depth of barista knowledge and shop managers, management's strategy in creating an image as a single origin shop to attract consumers can also be an indicator of the existence of connoisseur consumers. Connoisseur consumers will prefer shops that have a reputation as a single origin compared to traditional coffee, which is in accordance with their characteristics concerning the origin of coffee and the quality of serving. The above results of the Spearman rank correlation analysis show that the significant value between the shop image variable with the number of customers below 0.05 equal to 0.032 . It means there is a correlation or relationship between two variables. Meanwhile, the value of the correlation coefficient is 0.493 . This means that there is a strong relationship between the management of the shop variable with the number of customers. If the image of a single origin shop is increasingly highlighted, the number of customers will also increase. 
In order to detect the presence of connoisseurs, a correlation between the variation of single origin coffee and SOCSs with the number of visitors was tested. Other than paying attention to the coffee they drink, CCs are usually happy to try new coffees. More varied the coffee served will attract more customers. Among single origin shop owners, the variety of coffee provided is one of the parts of the way they attract customers, especially coffee lovers. Correlation test on the significance value of the variable variation of coffee with the number of customers is below 0.05 equal to 0.003 . It can be said that the two variables are correlated with each other. Meanwhile, the value of the correlation coefficient is 0.644 , which means that the relationship or correlation between the variables of Shop Marketing with Number of Customers has a strong correlation. So, more varied the coffee provided by SOCS will increase the potential of the number of customers.

In order to strengthen the existence of CCs, we also verify the characteristics of visitors, whether it reflects the view that connoisseurs can build a cross-professional customer community or not. The survey results show that the category of consumers who have the highest percentage value in visiting coffee shops comes from friend (21\%), meeting (18\%), and club (12), the data shows that connoisseurs truly contribute to building customer communities across professions as presented by Quintão et al. (2018) [33]. Meanwhile, consumers who come by chance alone are only 16\%, most consumers have a good relationship with the shop manager, barista, or fellow customers. This shows that connoisseurs really exist to build a customer community for the shop. Detailed data on consumer relations with shop and barista manager can be seen in detail in figure 3 .

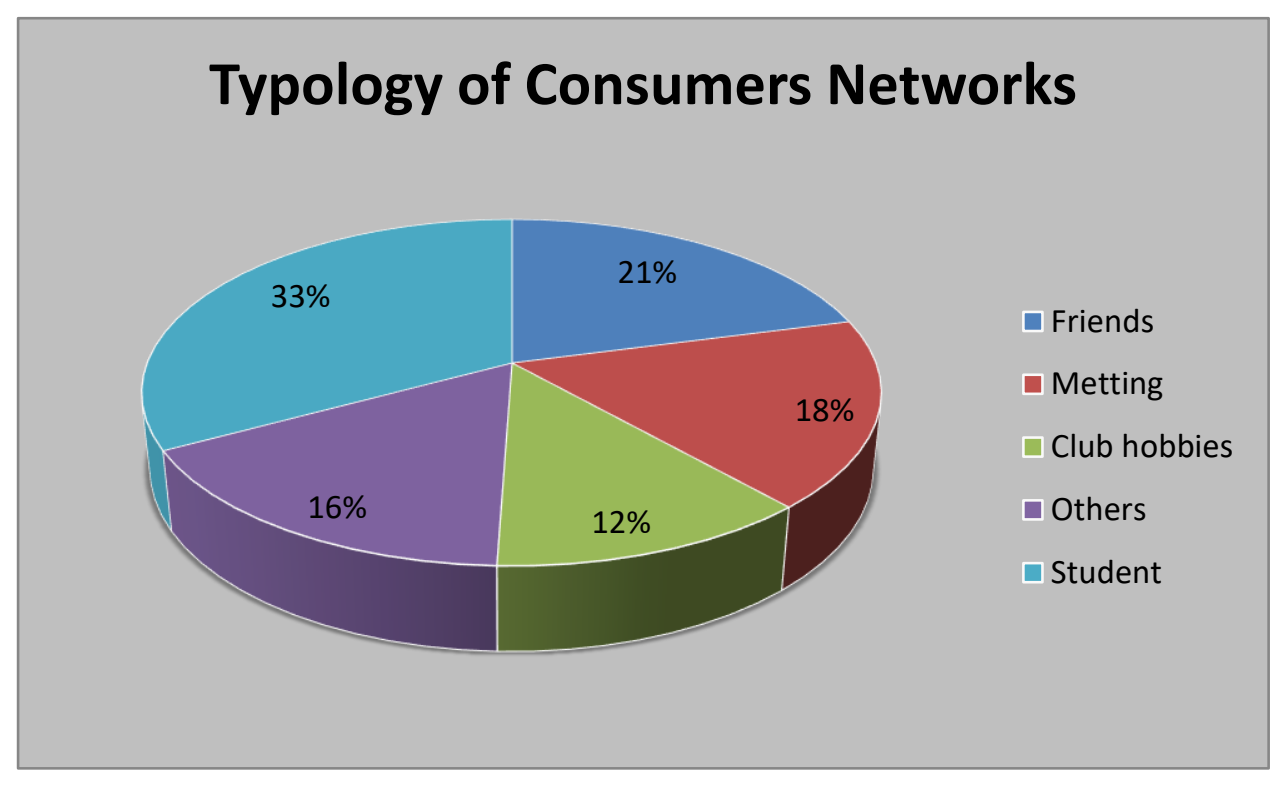

Figure 3. Relationship between baristas and shop visitor

\subsection{Sustainable consumption of Single Origin Coffee Shop}

The relationship between connoisseur and coffee consumption sustainability cannot be directly measured. The measurement is done through the change of management behavior to fulfill more sensitive connoisseur needs on the sustainability issues. For example, the shop must be able to explain why the price of coffee they offer is more expensive than the same coffee in the market. Consumers will perceive the goods they buy as expensive if there is no adequate explanation. This will affect their decision to buy single origin coffee. Relatively complex service and serving technique comparing to regular coffee are deemed to be not enough by the consumers to rationalize the price of coffee that can double and triple from the regular coffee shops. Matrix at table 2 gives the 
illustration of the relationship between four sustainable dimensions with three main activities of single origin coffee business.

Table 3. Continuous behavior by shop management to meet CCs needs

\begin{tabular}{|c|c|c|c|c|}
\hline $\begin{array}{l}\text { Sustainability } \\
\text { dimension }\end{array}$ & $\begin{array}{l}\text { Transferring } \\
\text { Green knowledge }\end{array}$ & $\begin{array}{l}\text { Saving energy } \\
\text { consumption }\end{array}$ & $\begin{array}{l}\text { Transparency in } \\
\text { business } \\
\text { processes }\end{array}$ & $\begin{array}{l}\text { Reducing waste } \\
\text { negative impacts } \\
\text { of waste }\end{array}$ \\
\hline Production & $\begin{array}{l}\text { Coffee shop } \\
\text { always provides } \\
\text { input to their } \\
\text { partner farmers to } \\
\text { produce high- } \\
\text { quality coffee } \\
\text { including organic } \\
\text { coffee to meet the } \\
\text { needs of } \\
\text { connoisseur } \\
\text { consumers }\end{array}$ & $\begin{array}{l}\text { The red picking } \\
\text { campaign will } \\
\text { maximize the } \\
\text { process of } \\
\text { forming coffee } \\
\text { fruit for more } \\
\text { optimal } \\
\text { production results }\end{array}$ & $\begin{array}{l}\text { Shops } \\
\text { farmers' green } \\
\text { bean with more } \\
\text { expensive price } \\
\text { than the market } \\
\text { price because the } \\
\text { farmers' } \\
\text { production } \\
\text { process requires } \\
\text { additional energy } \\
\text { to meet quality } \\
\text { standards }\end{array}$ & $\begin{array}{l}\text { Waste of green } \\
\text { bean processing } \\
\text { such as coffee skin } \\
\text { can be used for } \\
\text { fertilizer and } \\
\text { livestock feed }\end{array}$ \\
\hline Consumption & $\begin{array}{l}\text { The shop always } \\
\text { promotes the } \\
\text { proper way to } \\
\text { drink coffee to } \\
\text { reduce the risk of } \\
\text { adverse effects for } \\
\text { consumers' health }\end{array}$ & $\begin{array}{l}\text { Drinking coffee } \\
\text { without sugar } \\
\text { reduces the need } \\
\text { for sugar at least } \\
\text { for coffee drinkers }\end{array}$ & $\begin{array}{l}\text { Single origin shop } \\
\text { always promotes } \\
\text { coffee from fair } \\
\text { market trade } \\
\text { which does not } \\
\text { harm farmers }\end{array}$ & $\begin{array}{l}\text { Some shop coffee } \\
\text { waste is used for } \\
\text { food and } \\
\text { cosmetics. Coffee } \\
\text { with poor quality } \\
\text { is processed into } \\
\text { cool brew }\end{array}$ \\
\hline $\begin{array}{l}\text { Marketing } \\
\text { Aspect }\end{array}$ & $\begin{array}{l}\text { The shop provides } \\
\text { an explanation } \\
\text { service about the } \\
\text { knowledge of } \\
\text { coffee single } \\
\text { origin that will } \\
\text { increase the } \\
\text { customer's } \\
\text { knowledge on } \\
\text { sustainable coffee }\end{array}$ & $-0-$ & $\begin{array}{l}\text { The shop } \\
\text { established } \\
\text { different price } \\
\text { standards } \\
\text { between regular } \\
\text { coffee and single } \\
\text { origin coffee as a } \\
\text { form of business } \\
\text { transparency }\end{array}$ & $-0-$ \\
\hline
\end{tabular}

Source: Primary data processed (2018)

Apart from the above three categories, identifying the sustainability of consumption of SOCSs can also be seen from how they build shop image as a marketing strategy. Some shops promote the concept of "locality" as a promotional tool to appreciate local culture and local farmers. Meanwhile, they use the term "guest coffee" to anticipate the demand for coffee products outside the region which is sometimes more popular. This coffee is usually only complementary. "Locality" branding is used relatively effective by SOCS because coffee naturally has a close bond to local culture in 
addition to the location where they grow. Hence, associating coffee with locality is quite effective as a promotional material.

Another branding strategy that also reflects sustainability consumption is raising issues of equity in coffee distribution. Certain terms that reflect their concerns about the issue of justice are often found both in their Instagram account and in writings posted on the shop's wall. Jargons such as "fair coffee", "don't drink the farmer's blood through coffee", or "a cup of justice" are a form of their expression to campaign for a transparent business form. Coffee shops also sarcastically comment on coffee business practices that they consider unfair with the term "Coffee is supposed to be grounded not cut" to illustrate that the sachet coffee produced by the factory is considered to be unfair.

SOCSs branding with "learning place", "place of sharing" or "gathering place" indirectly supports sustainability consumption. SOCSs deliberately attract consumers of younger generation and groups of hobbies with the branding. The increasing number of Indonesian middle classes that have grown very fast in the past ten years ago is a potential market for SOCS. Hence, the branding is quite effective. There has been no empirical evidence of the effect of SOCSs on decreasing deviant behaviors such as "gangsters", drugs, or other crimes as a characteristic of urban communities. However, the existence of SOCSs as new media to socialize reduces the potential of younger people to carry out these actions.

Education is also a common promotional topic among SOCSs as an effort to attract customers. They used to compare their shops by posting consistent educational content about coffee using social media. The spread of knowledge about the single origin, good coffee production methods, and good coffee brewing processes will increase their customers' knowledge about single origin coffee. Although it is not directly targeting sustainable consumption, this branding certainly opens opportunities for ordinary consumers to increase their interest in coffee to become connoisseur consumers. The effort of SOCSs is quite serious in building the image of its shop to get good loyalty from its consumers in accordance with the findings of (Han et al., 2018a) that loyalty is an interrelation between cognitive and affective factors. Hence, building an image is very important.

So, it is very clear that CCs facilitates SOCSs to encourage sustainability consumption because their presence can attract other communities to become consumers, other than directly contributing to shop's income. Even with small existence, their contribution is considered adequate to keep the shop from going bankrupt. On the other hand, a community that is interested in it is a bonus for SOCSs. One of the managers of SOCSs said "they (CCs) are the savior of our cash flow other than to attract their friends to join. Their arrival at our shop also encouraged us to continue to improve our coffee knowledge to avoid embarrassment. Obviously, the two functions played by CCs as consumers are the drivers of the shop's income and as a symbol of their coffee lovers. They become the attraction for regular consumers to come to the shop.

\subsection{Connoisseur consumer, sustainability and Dynamics capabilities}

\subsubsection{Connoisseur and Sensing Process}

The existence of CCs facilitates the shop to map market segmentation, their preferences, as well as a mapping which community groups should be targeted by their promotion. Thus, it will be easier for the coffee shop to synthesize and classify what resources are needed to compete. It will be easier for them to record the required needs starting from the procurement of raw materials to marketing strategy. The trend of the type of coffee sought from the market is communicated by CCs, making it easier for the shop to plan the needs of the following month to the following year. Hence, they can build contact with farmers, green bean providers or even fellow shop owners early on. It will be more 
difficult for the regular coffee shop to do the mapping because they only rely on differences in presentation. Thus, their competitiveness becomes lower. The sensitivity of the company which is driven by the existence of CCs will surely not be obtained by regular coffee shops. Hence, they have to analyze the market trends themselves in the future.

In addition, SOCSs are also very familiar with the latest communication technology, especially social media, to identify opportunities. The use of these technologies also facilitates the identification process of opportunities especially to find out the tendency of market trends [40], [51]. For example, SSCS often opens polls to audiences to assess new products before they are launched. This is to find out how much customer interest through social media. The Instagram story is the shop's favorite media to introduce their new single origin products.

Polls are very efficient to map the market while avoiding deterioration in the reputation of the new products if there is a lack of customer response because it has been announced from the beginning that the product is tentative. It will be continued if there is a positive response. The use of this technology will provide convenience to managers in mapping the desires of consumers without requiring much energy and costs, compared to traditional method. Hence, technology allows managers to process identification of opportunities easily, quickly, and cheaply [37].

\subsubsection{Connoisseur and Seizing Process}

The resources that have been mapped in the above require special strategies to be used by the company. One of the strategies built by SOCSs is designing shop businesses by utilizing the resources they controlled such as coffee knowledge, single origin coffee networks, friendships, and approaching groups of hobbies to get customers. The way SOCSs build the image by selling the coffee fairly and locally is one of the methods to do market segmentation to attract certain customers. So, SOCSs in Indonesia intentionally position themselves as different shops than most of the traditional shops that have existed before, in some cases they also make a difference with the pattern of international network shops such as Starbuck and Kopi Tiam. This is in line with the finding of [22], [32] where the culture of coffee does not always follow a mainstream pattern such as Starbuck. However, it will always have a strong sense of locality as part of cultural alternatives.

The strategy for SOCSs by designing new businesses segment is their way to win the competition with regular coffee shops and international network shops. As we know, regular coffee shops in the past ten years have also transformed their businesses which were not so impressive for traditional shops. However, it is more like a modern café equipped with various modern snacks. They also provide free Internet facility to meet the communication needs of younger customers and build a more comfortable atmosphere in accordance with the demands of today's generation. Building an image as a coffee shop with good quality coffee and giving other ethical touches are accurate strategies of SOCSs to differentiate themselves from existing competitors.

In addition to designing businesses that are more segmented on CCs and the community of hobbies and the younger generation, SOCSs also build the characteristics of their shop by designing shop, giving variations of coffee served and giving typical service model. In addition, they usually serve some special coffee that can only be enjoyed among their own community. Some coffee networks conduct business contract with certain farmer groups and develop brands that are only sold in their outlets. It became their specific competitiveness. Usually, they provide assistance to farmers intensively about coffee processing to get quality, aroma, and taste according to market needs. Using this strategy is a precise way for companies to seize existing resources. Thus, other people will not be able to replace it since because they use an exclusive business relationship pattern. 


\subsubsection{Connoisseur and Transforming Process}

Transformation process carried out by SOCSs caused by the growth of fairly large CCs in the past ten years are also due to a shift in the impression that coffee is identical to old, masculine, ancient tradition. Hanging out in a coffee shop, especially in single origin shops, is a new lifestyle for the younger generation. In addition, old and masculine impressions begin to erode. It is clear that the role of SOCSs is to change that impression by showing their female customers picture on a social media page. Coffee is a cross-generation drink. SOCSs are also a convenient place for anyone including women. As we know, ten years ago before the coffee culture developed in Indonesia, women who spent their time in coffee shops would be considered as unusual. The impression was the same even in a big city like Jakarta as a cosmopolitan city. In some shops, since the coffee culture boomed around the 2000s, they began employing women as baristas or shopkeepers.

Another corporate culture that has changed to face competition is the principle of increasing added value rather than selling price monopoly. This is different from regular shops that are still focused on providing low prices to customers which causing relatively small sales margin. This added value can be in the form of service, quality of coffee taste, free Wi-Fi facility and the convenience of the shop's atmosphere. This increased added value is believed to be far better than competing prices because they are well aware that their segmentation is not a customer who is hunting for price incentives. This situation cannot be separated from the existence of CCs as their customers whose numbers continue to increase along with social contacts occurring in shops among fellow customers.

Another transformation carried out by SOCSs is building networks among them both as a means of communication and building a good business environment. This network is also directly used to exchange information and even information on the procurement of raw materials. If regular shop relies on raw materials from the market, then a single origin shop uses the network more to fulfill their raw materials needs. The alliance of the owners of the single origin shop is also used to procure shop's equipment as well as cooperation in following certain moments for the purpose of promoting coffee culture.

\section{Discussion}

Seeing the existence of promising CCs of more than $20 \%$ of total shop visitors, it is very natural for the shop to make various efforts to meet the tastes of CCs starting from providing a large variety of single origin coffee, building a shop that cares about farmers, also developing shop relationship with more open and egalitarian customers. It is not just a number, CCs are also able to build a community both with regular consumers or fellow CCs. Thus, its existence has two attractions for regular visitors, friends, and coffee lovers. This is in line with the findings of the survey where friend, meeting, and club are the most frequent visitors of the shop. This confirms the theory that CCs are able to build sub-cultures and social capital. Hence, they can build communities both with regular consumers and outstanding professionals [33], [36].

When viewing the categories of connoisseur associated with the visit, those four indicators have a close relationship with the number of visits. Although we do not specifically see the existence of CCs, the close relationship between these categories can be used as an initial indication that CCs are indeed able to attract visitors, both regular visitors, and professional coffee lovers. Discussions with baristas in some shops also show similar conditions where consumers are increasingly critical of the coffee they serve. The manager also asks them to always ask customers' opinion on whether the coffee 
they served satisfied them or not. By seeing this data, it can be seen if the manager consciously maps the consumer characteristics and identifies the level of satisfaction. In DCs theory, mapping and resource classification activities are carried out by owners of SOCSs as a sensing process.

The existence of these CCs is responded by SOCSs by building a business that is indirectly related to sustainability attribute. The process of transferring green knowledge to baristas so that they can explain to customers who ask about coffee is an indication that CCs indirectly drive the sustainability consumption. The demand to obtain good raw material has encouraged SOCSs to provide assistance to the farmers either in a group or personal so that they can make efficient energy consumption at the farmer level in processing good coffee beans. They inevitably have to teach environmentally friendly production methods and hygienic coffee bean processing. This will encourage sustainability at the farmer level. The social interaction that they built with farmers, as well as other shops, has encouraged an increase in the price of coffee beans at the farmer level. This relationship causes farmers to know the margins obtained by SOCSs, forcing the shop to increase their sharing by buying with far more expensive prices than market prices. Thus, the existence of CCS has indirectly encouraged transparency in the SOCSs business process which is theoretically an indication of sustainability.

The next response carried out by SOCSs was to design their business to fit the characteristics of CCs starting from building shop image, providing baristas with sufficient capabilities, and building networks to the farmer level to guarantee the claims as SOCSs. Although they are not exclusive to certain segments such as specialty shop for CCs or coffee experts, opening up the possibility to sell drinks not related to coffee is very much avoided especially traditional drinks. At the most, they will exploit various types of espresso-based drinks such as cappuccino, latte, ice coffee, and milk coffee. However, they try to make the non-dominant strategy to maintain the impression of SOCSs. They also modified some of the food menus where SOCSs should not be shifted into café and not coffee shops anymore.

This business design shows effective seizing process in which CCs existence as the main resources can be maintained. At the same time, they open the opportunity for most the consumers. Choosing a shop theme by promoting locality, using organic promotion, fair trade, and other ethnic attributes is also a form of seizing other SOCSs. Meanwhile, the efforts of SOCSs to mobilize alliances with fellow shops and build networks to farmers are a form of transformation of the company they use. The efforts of the owners of SOCSs to build different cultures within their company organizations that reflect attention to ethic attributes are part of the transforming company.

\section{Conclusions}

This research confirms that CCs are an important component of the sustainability of SOCs amid intense competition both with traditional coffee shops and international coffee shop chain. The analysis on the attributes related to CCs such as the improvement of manager's knowledge on coffee, the image of the coffee shop, coffee variation, barista's communication skills, and quality of coffee serving technique show a positive relationship with the number of consumers. This clearly shows that CCs are part of the consumer. The reason is that these attributes related to CCs preferences. These findings are in line with an opinion by [33] which stated that CCs are agents who are able to build communities both with professionals and regular consumers to form new sub-culture. In addition, the survey results on the characteristics of visitors show that friends, meetings, and the clubs are ranked highest. Hence, it has confirmed this finding. 
The potential of their existence to more than $20 \%$ of visitors was realized by shop owners until they designed their business according to the needs of CCs. The existence of CCs, directly and indirectly, encourage the sustainability of consumption because SOCSs carry out the transferring green knowledge process, saving energy consumption, increasing the transparency of business processes, and reducing the negative impact of waste in its business processes on three main aspects of business namely production, consumption, and distribution. Loyalty and high concern for ethic attributes of coffee are referred to by SOCSs to design and build more environmentally friendly businesses to adapt to these attributes.

At the same time, the existence of CCs also makes it easier for SOCSs to map resources, acquire these resources and design company businesses by utilizing these resources appropriately. They are also able to transform corporate culture into more adaptive to consumer demands. At the same time, SOCSs also built alliances with fellow shop owners, building networks to farmers to continue to improve their competitiveness. Hence, CCs are very important, both directly and indirectly pushing the sustainable consumption and making it easier for SOCSs to build strong dynamic capabilities in order to compete with traditional shops or international network shops. Based on the above findings, more in-depth research on the standard character and number of CCs is needed as well as their contribution to the revenue structure of SOCSs. Meanwhile, connoisseur customers' support is practically capable of helping the SOCSs in improving their DCs to be more potential in improving the sustainable consumption of coffee commodity in the future.

Author Contributions: Conceptualization, methodology, and supervision of this manuscript were done by Heiko Faust and Mangku Purnomo, while investigation, resources, validation, software and data curation were done by Fenna Otten, Sugeng Riyanto, and Medea Ramadani Utomo. Formal analysis and writing-original draft preparation was done by Mangku Purnomo including editing and visualization.

\section{Funding}

This research has no external funding.

\section{Acknowledgments}

The funding grant from the Indonesia Ministry of Higher Education and Research and Brawijaya University Research Fund are greatly appreciated.

\section{Conflicts of Interest}

The authors declare no conflict of interest.

\section{References}

[1] G. Gallenti, S. Troiano, M. Cosmina, and F. Marangon, "Ethical and sustainable consumption in the Italian coffee market : a choice experiment to analyse consumers ' willingness to pay 1," Riv. di Econ. Agrar., vol. LXXI, no. 2, pp. 153-176, 2016.

[2] L. F. Samper and X. F. Quinones-Ruiz, "Towards a Balanced Sustainability Vision for the Coffee Industry," Resources, vol. 6, no. 17, pp. 1-28, 2017.

[3] W. S. Sepúlveda, L. Chekmam, M. T. Maza, and N. O. Mancilla, “Consumers' preference for the origin and quality attributes associated with production of specialty coffees: Results from a cross-cultural study," Food Res. Int., vol. 89, pp. 997-1003, 2016.

[4] F. Edward, "Quality and Inequality: Taste, Value, and Power in the Third Wave Coffee Market," Cologne, MPIfG Discussion Paper, No. 17/4, 2017.

[5] T. Clark, Starbucked: A Double Tall Tale of Caffeine, Commerce, and Culture. New York: Little, Brown, 2007.

[6] G. Dicum, “Colony in a Cup," Gastronomica, vol. 3, no. 2, pp. 71-77, 2003. 
[7] D. Kjeldgaard and J. Ostberg, "Coffee Grounds and the Global Cup: Glocal Consumer Culture in Scandinavia," in Advances in Consumer research, vol. 8, M. Stefania Borghini, Mary Ann McGrath, and Cele Otnes, Duluth, Ed. Association for Consumer Research, 2007, pp. 145-149.

[8] A. Samoggia and B. Riedel, “Coffee consumption and purchasing behavior review : Insights for further research," Appet. J., vol. 129, no. April, pp. 70-81, 2018.

[9] M. Purnomo, “Contesting Indonesia's Single Origin Coffee Market: A Dynamic Capabilities Perspective," Asian Soc. Sci., vol. 14, no. 8, pp. 91-101, 2018.

[10] L. T. Raynolds, “Mainstreaming Fair Trade Coffee: From Partnership to Traceability,” World Dev., vol. 37, no. 6, pp. 1083-1093, 2009.

[11] J. Neilson, J. Wright, and L. Aklimawati, “Geographical indications and value capture in the Indonesia coffee sector," J. Rural Stud., vol. 59, no. May 2017, pp. 35-48, 2018.

[12] W. Vellema, A. Buritica Casanova, C. Gonzalez, and M. D'Haese, “The effect of specialty coffee certification on household livelihood strategies and specialisation," Food Policy, vol. 57, pp. 13-25, 2015.

[13] L. Schüßler, “Protecting 'Single-Origin Coffee' within the Global Coffee Market: The Role of Geographical Indications and Trademarks," Estey Cent. J. Int. Law Trade Policy, vol. 10, no. 1, pp. 149$185,2009$.

[14] D. Barjolle, X. F. Quiñones-Ruiz, M. Bagal, and H. Comoé, “The Role of the State for Geographical Indications of Coffee: Case Studies from Colombia and Kenya," World Dev., vol. 98, pp. 105-119, 2017.

[15] R. Teuber, "Geographical Indications of Origin as a Tool of Product Differentiation : The Case of Coffee," Giessen, 33, 2007.

[16] M. Vicol, J. Neilson, D. Faila, S. Hartatri, and P. Cooper, “Upgrading for whom ? Relationship coffee , value chain interventions and rural development in Indonesia," World Dev., vol. 110, pp. 26-37, 2018.

[17] B. R. Wilson, J. F. Conley, T. M. Harris, and F. Lafone, "New terrains of taste : Spatial analysis of price premiums for single origin coffees in Central America," Appl. Geogr., vol. 35, no. 1-2, pp. 499-507, 2012.

[18] J. Rath and W. Gelmers, "Trendy coffee shops and urban sociability," in Urban Europe: Fifty Tales of the City, I., V. Mamadouh and A. Van Wageningen, Eds. Amsterdam: Amsterdam University Press B.V, 2016, pp. 123-131.

[19] H. Han, H. N. Nguyen, H. Song, B. Chua, S. Lee, and W. Kim, "Drivers of brand loyalty in the chain coffee shop industry," Int. J. Hosp. Manag., vol. 72, no. December 2017, pp. 86-97, 2018.

[20] L. Al-Rasheed, Madawi; Al-Rasheed et al., "Coffeehouses and Culture," J. Consum. Cult., vol. 70, no. 4, pp. 746-761, 2007.

[21] E. Argan, Metin, Akyildiz, Muge, Burcu, Ozdemir, Bas, Avsar, Akkus, "Leisure Aspects of Turkish Coffee Consumption Rituals: An Exploratory Qualitative Study," Int. J. Heal. Econ. Dev., vol. 1, no. 1, pp. 26-36, 2015.

[22] H. Grinshpun, “Deconstructing a global commodity: Coffee, culture, and consumption in Japan," J. Consum. Cult., vol. 14, no. 3, pp. 343-364, 2014.

[23] A. Jeffrey, L. A. Staeheli, C. Buire, and V. Čelebičić, “Drinking coffee, rehearsing civility, making subjects," Polit. Geogr., pp. 1-10, 2017.

[24] C. Bacon, "Confronting the coffee crisis: Can Fair Trade, organic, and specialty coffees reduce smallscale farmer vulnerability in Northern Nicaragua?," World Dev., vol. 33, no. 3, pp. 497-511, 2005.

[25] D. L. Levy, J. Reinecke, and S. Manning, “The Political Dynamics of Sustainable Coffee: Contested Value Regimes and the Transformation of Sustainability," J. Manag. Stud., vol. 53, no. 3, pp. 364-401, 2016.

[26] S. Ang et al., "Political Dynamics of Sustainable Coffee and Contested Value Regimes.," J. Manag. Stud., vol. 53, no. 3, pp. 364-401, 2016. 

SYSTEMIC CYCLES AND BRAUD EL'S LAYERS OF ANALYSIS," Am. Sociol. Assoc., vol. XVII, no. 1, pp. 58-88, 2011.

[28] W. B. Sunarharum, D. J. Williams, and H. E. Smyth, "Complexity of coffee flavor: A compositional and sensory perspective," Food Res. Int., vol. 62, pp. 315-325, 2014.

[29] C. M. Tucker, Coffee Culture: Local Experiences, Global Connections. New York: Routledge, 2012.

[30] T. Wright and A. Rahmanulloh, “Indonesia Coffee Annual Report 2017," 2017.

[31] USDA, “Coffee: World Markets and Trade," 2018.

[32] H. Grinshpun, "The Drink of the Nation? Coffee in Japan's Culinary Culture," in Feeding Japan: The Cultural and Political Issues of Dependency and Risk, Palgrave Macmillan, Cham., 2017, pp. 167-190.

[33] R. T. Quintão, E. P. Z. Brito, and R. W. Belk, "Connoisseurship Consumption Community and Its Dynamics," Rev. Bras. Gest. Negocios, vol. 19, no. 63, pp. 48-64, 2017.

[34] E. L. O'Connor, L. Sims, and K. M. White, "Ethical food choices: Examining people's Fair Trade purchasing decisions," Food Qual. Prefer., vol. 60, no. October 2016, pp. 105-112, 2017.

[35] R. T. QUINTÃO, E. P. Z. BRITO, and R. W. BELK, "the Taste Transformation Ritual in the Specialty Coffee Market," Rev. Adm. Empres., vol. 57, no. 5, pp. 483-494, 2017.

[36] J. Strong, "Educated tastes : food, drink, and connoisseur culture," p. 292, 2011.

[37] D. J. Teece, “Business models and dynamic capabilities," Long Range Plann., vol. 51, no. 1, pp. 40-49, 2017.

[38] A. McKelvie and P. Davidsson, "From Resource Base to Dynamic Capabilities: an Investigation of New Firms," Br. J. Manag., vol. 20, no. s1, pp. S63-S80, 2009.

[39] D. Ringov, “Dynamic capabilities and firm performance," Long Range Plann., vol. 50, no. 5, pp. 653-664, 2017.

[40] E. T. G. Wang, H. F. Hu, and P. J. H. Hu, “Examining the role of information technology in cultivating firms' dynamic marketing capabilities," Inf. Manag., vol. 50, no. 6, pp. 336-343, 2013.

[41] S. M. Geiger, D. Fischer, and U. Schrader, "Measuring What Matters in Sustainable Consumption: An Integrative Framework for the Selection of Relevant Behaviors," Sustain. Dev., vol. 26, pp. 18-33, 2018.

[42] M. Hamdoun, C. J. Chiappetta Jabbour, and H. Ben Othman, "Knowledge transfer and organizational innovation: Impacts of quality and environmental management," J. Clean. Prod., vol. 193, pp. 759-770, 2018.

[43] S. Sareen and H. Haarstad, "Bridging socio-technical and justice aspects of sustainable energy transitions," Appl. Energy, vol. 228, no. July, pp. 624-632, 2018.

[44] J. Stephenson, "Sustainability cultures and energy research: An actor-centred interpretation of cultural theory," Energy Res. Soc. Sci., vol. 44, no. September 2017, pp. 242-249, 2018.

[45] T. A. Gardner et al., "Transparency and sustainability in global commodity supply chains," World Dev., 2018.

[46] V. Filimonau, M. Krivcova, and F. Pettit, "An exploratory study of managerial approaches to food waste mitigation in coffee shops," Int. J. Hosp. Manag., vol. 76, no. March 2018, pp. 48-57, 2019.

[47] K. Govindan, "Sustainable consumption and production in the food supply chain: A conceptual framework," Int. J. Prod. Econ., vol. 195, no. November 2015, pp. 419-431, 2018.

[48] C. Kohtala, "Addressing sustainability in research on distributed production: An integrated literature review," J. Clean. Prod., vol. 106, pp. 654-668, 2015.

[49] P. Mayring, "Qualitative Content Analysis.," Forum Qual. Soc. Res., vol. 1, no. 2, pp. 39-62, 2000.

[50] L. S. Nowell, J. M. Norris, D. E. White, and N. J. Moules, "Thematic Analysis: Striving to Meet the 
Trustworthiness Criteria," Int. J. Qual. Methods, vol. 16, no. 1, pp. 1-13, 2017.

[51] A. Jantunen, A. Tarkiainen, S. Chari, and P. Oghazi, “Dynamic capabilities, operational changes, and performance outcomes in the media industry," J. Bus. Res., vol. 89, no. February, pp. 251-257, 2018. 